\title{
O Tribunal Penal Internacional e os desafios da jurisdição internacional contemporânea na implementação dos Direitos humanos
}

\author{
The International Criminal Court and the challenges of \\ contemporary international jurisdiction on the implementation of \\ Human rights
}

\author{
Dirceu Pereira Siqueira ${ }^{1}$ \\ Ligia Maria Lario Fructuozo ${ }^{2}$
}

\begin{abstract}
RESUMO: O Tribunal Penal Internacional representa a concretização de um anseio antigo da comunidade internacional, no sentido de proporcionar meios para a punição dos responsáveis acusados de cometerem os crimes mais graves em violação aos direitos humanos, bem como de se revelar como mecanismo de proteção efetiva desses direitos.No entanto, ainda hoje, alguns obstáculos precisam ser superados e, muitas vezes, estes resultam de suas próprias características constituintes e de aspectos específicos do direito e relações internacionais. Nesse contexto, o presente trabalho realizará uma análise sobre o processo que levou ao desenvolvimento do direito internacional dos direitos humanos, a partir de seus principais antecedentes na história da humanidade até chegar ao momento presente. Abordará, também, como se deu a implementação do Tribunal Penal Internacional, órgão criado para processar os criminosos acusados de cometerem os maiores crimes em atentado aos direitos humanos. Por fim, será examinado quais as motivações que justificaram a criação do Tribunal, a sua vulnerabilidade em razão das suas características bem como os feitos alcançados até o momento. Para tanto, será utilizado o método analítico dedutivo, que partirá da análise geral da evolução da necessidade de proteção internacional dos direitos humanos até chegar na criação do TPI como ponto máximo desse processo. Também será empregado o método dialético para considerar o contexto social e político desta questão, a fim de apontar soluções às críticas geradas.
\end{abstract}

Palavras-chave: Direitos Humanos. Tribunal Penal Internacional. Direito Internacional.

\begin{abstract}
The International Criminal Court represents the achievement of a longstanding wish of the international community to provide the means to punish those accused of committing the most serious crimes in violation of human rights and to be a mechanism for

\footnotetext{
${ }^{1}$ Doutorado em Sistema Constitucional de Garantia de Direitos pelo Instituição Toledo de Ensino; Coordenador do Curso de Mestrado em Direito do Centro Universitário Cesumar - UniCesumar.

${ }^{2}$ Especialização em Direito Penal e Processo Penal pelo Centro Universitário Antônio Eufrásio de Toledo de Presidente Prudente; Supervisora de Prática Profissional do Centro Universitário Antônio Eufrásio de Toledo de Presidente Prudente.
} 
effective protection of human rights. However, even today, some obstacles need to be overcome, and these often result from their own constituent characteristics and from specific aspects of international law and relations. In this context, the present work will analyze the process that led to the development of international human rights law, from its main antecedents in the history of humanity until reaching the present moment. It will also address the implementation of the International Criminal Court, a body created to prosecute criminals accused of committing the greatest crimes of human rights abuses. Finally, it will examine the motivations that justified the creation of the Court, its vulnerability due to its characteristics as well as the achievements to date. To do so, the analytical method of deduction will be used, starting from the general analysis of the evolution of the need for international protection of human rights until the creation of the ICC as the maximum point of this process. The dialectical method will also be used to consider the social and political context of this issue, in order to point out solutions to the criticisms generated.

Keywords: Human Rights.International Criminal Court.International Rights.International Law.

\section{INTRODUÇÃO}

O Tribunal Penal Internacional, uma das instituições internacionais principais que foram criadas no final do século $\mathrm{XX}$, representa hoje um dos atores fundamentais na proteção dos direitos humanos, em especial quando a gravidade das violações desses direitos atinge um nível tão alto que constituem crimes internacionais.

Nesse sentido, o presente artigo tem como escopo a demonstração de que o Tribunal Penal Internacional, criado em 1998, representa um mecanismo importante na busca da imprescindível efetivação da proteção internacional dos direitos humanos.

Entretanto, a mera criação deste órgão não supre totalmente as necessidades atuais da comunidade internacional, visto que sua atuação é limitada, principalmente no que diz respeito aos fatos processados e os Estados submetidos a sua incidência.Mesmo assim, representa importante avanço na agenda internacional dos direitos humanos, na medida em que tenta consagrar o Princípio da Justiça Universal e força os Estados a colaborarem e flexibilizarem sua soberania para atender à proteção dos direitos humanos de seus cidadãos.

Ao longo do trabalho relatou-se o processo que levou à internacionalização dos direitos humanos, dando destaques aos principais marcos históricos na afirmação e construção desses direitos desde a Antiguidade até o momento em que se criou o Tribunal Penal Internacional. Como antecedentes importantes são citados os Tribunais de Nuremberg e de 
Tóquio, que foram criados para julgar e punir os perpetradores dos crimes mais bárbaros cometidos durante a Segunda Guerra, além dos Tribunais para a ex-Iugoslávia e para Ruanda, instituídos para julgar pessoas responsáveis de cometerem violações aos direitos humanos durante conflitos internos de ambas as região.

Também foi considerado o contexto jurídico e político em que se deu a criação do Tribunal para que seja possível compreender o papel e a relevância deste organismo no cenário internacional para a proposta de uma justiça universal. E, importante destacar que, embora haja limitações em sua atuação, devido principalmente ao fato de que os Estados não desejam ceder parte de sua soberania aos ditames internacionais, o Tribunal representa o anseio de uma forma inovadora de efetivação da proteção dos direitos humanos no plano internacional.

Aí se dá a relevância do tema, pois o Tribunal Penal Internacional representa e fortalece a ideia da proteção plena e efetiva dos Direitos Humanos, matéria que foi sendo internacionalizada ao longo dos anos e da evolução do próprio direito internacional.Neste contexto, o assunto é atual, relevante para o mundo jurídico e objetiva levantar questões gerais e específicas, aprofundando o estudo do direito internacional dos direitos humanos e contribuir para o debate com a intenção de solidificar a existência, importância e atuação deste órgão.

Ao final, o trabalho ainda analisa quais os desafios que o Tribunal Penal Internacional encontra hoje em dia para de fato se concretizar no mecanismo idealizado, sendo importante que destacar que a cooperação entre os Estados é comportamento que tem que ocorrer para que o TPI exerça sua jurisdição de forma complementar. Os Estados precisam adequar seus ordenamentos internos para cederem parte de sua soberania para o Tribunal, que desta forma, poderá promover uma justiça efetiva e de caráter universal.

Durante o exame dessas questões foi feita uma análise analítico-dedutiva no sentido de investigar e reconstruir o caminho da evolução do processo de internacionalização dos direitos humanos até chegar ao momento presente onde a atuação do Tribunal Penal Internacional, apesar de se mostrar delicada, apresenta uma expectativa positiva no futuro. Para a apreciação com relação ao que era esperado do Tribunal e ao que efetivamente foi, prevalecerá um ponto de vista crítico e dialético sobre os fatos.

O presente trabalho foi elaborado com base numa consulta bibliográfica e documental, com doutrinas nacionais e internacionais. Foram utilizados na pesquisa, ainda, os 
tratados internacionais, documentos das Nações Unidas, do Tribunal Penal Internacional, artigos de revistas, físicos e eletrônicos, filmes, documentários, entre outros.

\section{O DESENVOLVIMENTO DO DIREITO INTERNACIONAL DOS DIREITOS HUMANOS}

É comum a afirmação equivocada de que o Direito Internacional é uma criação recente, quando na realidade sua origem na verdade seria imprecisa, pois remonta ao momento em que os seres humanos se organizaram em comunidades num determinado território e tiveram que lidar entre si sobre questões referentes ao comércio, guerras, fronteiras e manutenção da paz.

De fato, os costumes de um povo é que são as fontes originárias de seu regramento interno e, posteriormente, quando em conflito ou convergência com os costumes de outro povo, surgea necessidade de se criar normas de aplicação internacional para resolver os conflitos existentes entre eles. Nesse sentido, importante mencionar que a palavra internacional foi gradativamente adquirindo o significado que apresenta hoje, na acepção de caráter mundial, global. Pois, o desenvolvimento da tecnologia permitiu que as pessoas viajassem para distâncias maiores, fato que as colocava em contato com sociedades mais ou menos evoluídas, o que fez com que os costumes fossem positivados de tal forma que dessem origem a uma lei internacional capaz de governar diversos estados e sociedades.

De encontro a essa ideia, Jeremy Sarkin (2007, p. 4) afirma:

In other words, local customs gave rise to the rules that had governed trade and other interactions between states. When the customs were adapted to smooth relationships. In many cases, societies found that their general practices and customs were sufficiently similar to be reconciled to the satisfaction of all parties involved. These practices slowly solidified into fabric of what we now call international law ${ }^{3}$.

\footnotetext{
${ }^{3} \mathrm{Em}$ outras palavras, os costumes locais deram origem as regras que governaram o comércio e outras interações entre os estados. Quando os costumes foram adaptados para suavizar relacionamentos. Em muitos casos, as sociedades descobriram que suas práticas e costumes gerais eram suficientemente semelhantes para serem reconciliados para a satisfação de todas as partes envolvidas. Essas práticas se solidificaram lentamente no tecido do que hoje chamamos de direito internacional. (tradução livre da autora)
} 
Como se nota, essas práticas e costumes foram se solidificando ao longo da existência da humanidade desde os seus primórdios e geraram o direito escrito. Tanto é verdade que em quase todos os grandes impérios - a exemplo de Grécia e Egito -é possível encontrar material literário que estabeleciam regras de como lidar com povos e território de outras nações, bem como com diplomatas visitantes.

No entanto, é possível afirmar que o nascimento das leis internacionais na forma como hoje conhecemos tiveram um marco importante, o qual se deu no século XVII (1648), após a Guerra dos Trinta Anos, onde países europeus assinaram o acordo de Paz de Westfália, marcando o detrimento do poderio da Igreja em favor da consolidação do poder dos Estados-nação da época. Em outras palavras, houve a consolidação da atual sociedade internacional, com o Estado moderno soberano e em pé de igualdade com os demais Estados (BOBBITT, 2003, p. 477).

Diante desse caráter soberano dos Estados, o conflito passou a ser elemento constante nas relações e inexistia, até então, uma forma pacífica para a resolução desses conflitos. Essas múltiplas entidades soberanas geravam "uma liberdade selvagem que reproduz o estado de natural desregramento" (FERRAJOLI, 2002, p.). Isso dá ensejo ao que Thomas Hobbes (2012) chamou de bellum omnium (guerra de todos), pois os Estados, na busca incessante de poder, apresentavam-se como leviatãs, dispostos à guerra a todo o momento.

Por isso, afirma-se que, a princípio, somente os Estados eram sujeitos do Direito Internacional, e o homem era visto como mero objeto desta lei, não tinha nenhum reconhecimento legal no palco internacional de seus direitos, "de tal modo que a maneira como uma nação tratava os seus próprios cidadãos era vista como uma matéria que fazia parte, exclusivamente, da jurisdição doméstica dos Estados” (HEGARTHY e LEONARD, 1999, p. 23).

Esse era um princípio geral no campo do Direito Internacional, conhecido como "Princípio da Soberania", onde os Estados eram impenetráveis a organismos externos, mesmo que ocorressem graves violações dos direitos do homem, cada qual tinha suas leis e suas penas e estas eram soberanas perante o mundo. Os assuntos internos eram tratados da forma como cada um queria e a interferência de forças exteriores era proibida (SILVA, 1999, p. 33-38). Nesse sentido a afirmação de Immanuel Kant é assertiva quando diz que "o maior 
problema para a espécie humana, a cuja solução a natureza a obriga, é alcançar uma ampla sociedade civil que administre universalmente o direito" (2003, p. 10).

Foi justamente o aumento da capacidade bélica das nações em conjunto com o incremento do poder e soberania dos Estados, que deram origem as duas grandes guerras mundiais. E, marcadas por todo tipo de violação aos direitos das pessoas, a partir desse momento é que começou a existir uma real preocupação com a proteção internacional dos direitos do homem, dando início ao chamado processo de internacionalização dos direitos humanos.

Antes, no entanto, é válido destacar que estes acontecimentos se tratam de marcos importantes dados no século XIX, mas têm-se exemplos de algum nível de proteção do ser humano desde muito antes, com a proibição da pirataria, proibição do comércio de escravos e proteção internacional das minorias (SARKIN, 2007).

O processo de internacionalização dos direitos humanos divide-se em duas grandes etapas: a primeira marcada pelo Direito Humanitário, a Liga das Nações e a Organização Internacional do Trabalho; e, a segunda desenvolvida num momento pós Segunda Guerra Mundial, como se verificará a seguir.

Pois bem. O Direito Humanitário ou Direito de Guerra teve origem em 1864, e compreendia "o conjunto das leis e costumes da guerra, visando a minorar o sofrimento de soldados prisioneiros, doentes e feridos, bem como as populações civis atingidas por um conflito bélico" (COMPARATO, 2010, p. 67). Passou a impor limites no plano internacional quanto à liberdade e soberania dos Estados, ainda que estivessem diante de um conflito armado. Ao proteger militares fora de combate e populações civis, durante a guerra, impôs uma regulamentação legal quanto ao uso da violência no campo internacional.

Nesse sentido, o primeiro documento jurídico normativo no âmbito internacional foi a Convenção de Genebra, assinada em 22 de agosto de 1864, somente por potências europeias, com o objetivo de "melhorar a sorte dos militares feridos nos campos de batalha" (Preâmbulo da Convenção de Genebra).

A formação dessa Convenção teve sua origem na Batalha de Solférino, relatada pelo suíço Henry Dunant em seu livro, publicado em 1862, chamado "Un Souvenir de Solférino" (Uma Recordação de Solférino). Em sua obra, o suíço relatou como fícou impressionado durante a batalha em 1859 ao ver milhares de soldados feridos serem abandonados à própria sorte pelos exércitos austríacos e franco-piemonteses. Organizou, 
então, um serviço de pronta assistência, juntamente com a população local, insistindo que todos os soldados feridos, de ambos os lados, deveriam ser tratados (COMPARATO, 2010, p. 186).

A Convenção de Genebra reconhecia em seu artigo $1^{\circ}$ as ambulâncias e hospitais como neutros, que deveriam ser respeitados e protegidos pelos beligerantes, assim como os enfermeiros e voluntários que socorressem os feridos deveriam ser respeitados e livres (artigo $5^{\circ}$ ). E o artigo $6^{\circ}$ previa que os militares feridos ou doentes seriam recolhidos e tratados, independentemente da nação ao qual pertencessem. Portanto, o Direito Humanitário criou, portanto, obrigações para os países que estavam em guerra ou não. Outro marco desse período foi acriação da Comissão Internacional da Cruz Vermelha, em 1880.

Após a Primeira Guerra Mundial, em 1919, foi criada a Liga das Nações e representa uma segunda etapa no processo de internacionalização dos Direitos Humanos e tinha como finalidade "promover a cooperação, paz e segurança internacional, aceitando a obrigação de não recorrer à guerra, procurando estabelecer relações amistosas entre as nações, visando à manutenção da justiça e com respeito às obrigações decorrentes de tratados" (Preâmbulo da Convenção da Liga das Nações).

Apesar da Convenção da Liga das Nações não conter nenhum dispositivo expresso que garantisse os direitos humanos, foi importante para a internacionalização desses direitos em alguns aspectos, pois, a Liga tinha um sistema de mandato, onde a administração das colônias pertencentes aos Estados que haviam sido derrotados na Primeira Guerra, passariam para o domínio dos países vitoriosos, que deveriam respeitar os direitos das populações dessas colônias, tais como liberdade de consciência e religião. Estipulava também que tais povos deveriam ser tratados equitativamente (HEGARTHY e LEONARD, 1999, p. 24-25).

Após a Primeira Guerra Mundial, também foi criada a Organização Internacional do Trabalho (OIT), antecedente que igualmente muito contribuiu para a formação do Direito Internacional dos Direitos Humanos e trazia como finalidade proteger em padrão internacional os direitos do trabalhador. A OIT tinha o "objetivo de estabelecer critérios básicos de proteção ao trabalhador, regulando sua condição no plano internacional, tendo em vista assegurar padrões mais condizentes de dignidade e de bem estar social" (MAZZUOLI, 2002, p. 214). 
Após esse período, pode-se afirmar que se iniciava o fim de uma época em que o homem era tratado como mero objeto da Lei Internacional, para se tornar a partir de agora sujeito de direito no âmbito internacional. Os indivíduos contam deste momento em diantecom uma "capacidade processual internacional" e os direitos humanos passam a não mais "se limitarem à exclusiva jurisdição doméstica, mas constituem matéria de legítimo interesse internacional" (PIOVESAN, 2012, p. 182-183).

Esse interesse se mostrou ainda mais forte e legítimo após a Segunda Guerra Mundial, poisem razão dos graves crimes cometidos contra o ser humano, a necessidade de sua proteção se tornou mais evidente do que nunca e, desta vez, os Estados, em sua maioria, estavam dispostos a fazer alterações e flexibilizações sobre suas considerações políticas.

\begin{abstract}
A segunda grande guerra, que ensanguentou a Europa entre 1939 a 1945, ficou marcada na consciência coletiva mundial por apresentar o ser humano como algo simplesmente descartável e destituído de dignidade e direitos. O que fez a chamada "Era Hitler" foi condicionar a titularidade de direitos dos seres humanos ao fato de pertencerem à determinada raça, qual seja, a "raça pura" ariana, atingindo-se, com isto, toda e qualquer pessoa destituída da referida condição. Assim, acabaram os seres humanos tornando-se refugiados e apátridas. E por faltar-lhes um vínculo com uma ordem jurídica nacional, acabaram não encontrando lugar (qualquer lugar) num mundo como o do século XX, totalmente organizado e ocupado politicamente. Consequentemente, tais vítimas do regime nazista acabaram tornando-se - de fato e de direito - desnecessárias porque indesejáveis erga omnes, não encontrando outro destino senão a própria morte nos campos de concentração (MAZZUOLI, 2009, p. 24-25).
\end{abstract}

Percebe-se que, “o nível sem precedentes de devastação da Segunda Guerra Mundial terá levado as potências aliadas a buscar concretizar a ideia de responsabilizar individualmente os agressores e os criminosos de guerra nazistas" (CARDOSO, 2012, p. 20) e com a desocupação dos territórios dominados pela Alemanha é que se (re)conheceu a amplitude dos crimes perpetrados.

Only after the Allies liberated German-occupied territories did they realize the extent of the atrocities committed. Thereafter, British and U.S. forces began to develop a list of suspected war criminals in order to separate them from other liberated prisoners. At that point, the British Government began to press the UNWCC to complete its work (BASSIOUNI, 1997, s.p.) ${ }^{4}$

\footnotetext{
${ }^{4}$ Somente depois que os Aliados libertaram os territórios ocupados pelos alemães eles perceberam a extensão das atrocidades cometidas. Depois disso, as forças britânicas e norte-americanas começaram a desenvolver uma lista de supostos criminosos de guerra para separá-los de outros prisioneiros libertos. Nesse ponto, o governo britânico começou a pressionar o UNWCC para concluir seu trabalho.
} 
A barbárie cometida durante a Segunda Guerra era inacreditável para a época. Foram incontáveis relatórios que descrevem os atos aterrorizantes cometidos, principalmente pelos alemães, sob o domínio de Hitler. Homens foram conduzidos para praças públicas onde foram metralhados, trucidados ou explodidos com granadas nas mãos. Mulheres foram mortas nas ruas, centenas de prédios e casas de judeus foram incendiadas, pessoas tinham que cavar sua própria sepultura, judeus foram levados para campos de concentrações em que se realizavam trabalhos escravos e foram mortos em câmeras de gases e crematórios, onde seriam cozidos gordura e ossos humanos para produzir sabão, lubrificantes e glicerina. Cadáveres ficavam nus e insepultos pelas ruas, crianças morriam de fome. Milhões de pessoas foram deportadas (POWER, 2004, p. 55-63).

Todo o gênero humano se sentiu atingido pelos delitos horrendos que ocorreram. Nesse momento, se fez necessário um reexame da ordem internacional e os Estados se viram obrigados a pensar em normativa internacional como meio de efetivar o respeito aos direitos humanos. Nesse ponto, os direitos humanos se tornaram uma preocupação comum entre os Estados e um dos principais objetivos da comunidade internacional.

Em outras palavras, não havia mais como afirmar a concepção tradicional de que somente Estados eram sujeitos de direitos e obrigações no plano internacional, ficando evidente a necessidade em rever determinados conceitos para que homens, juntamente com os Estados, passassem a ser sujeitos de direito internacional, mormente quanto à proteção internacional dos direitos humanos.

\begin{abstract}
A necessidade de uma ação internacional mais eficaz para a proteção dos direitos humanos impulsionou o processo de internacionalização desses direitos, culminando na criação da sistemática normativa de proteção internacional, que faz possível a responsabilização do Estado no domínio internacional, quando as instituições nacionais mostram falhas ou omissas na tarefa de proteção dos direitos humanos (PIOVESAN, 2012, p. 185).
\end{abstract}

Após o período das Guerras, reconheceu-se o imperativo e urgência em reconstruir o direito internacional, observando-se os direitos dos seres humanos. O homem, neste momento, passava a ser sujeito de direitos e os acontecimentos trágicos vividos nos 
anos anteriores deixaram claro que a reconstrução de ideias e conceitos internacionais eram inevitáveis.

\begin{abstract}
Las atrocidades y abusos que hanvictimadoenlas últimas décadas millones de seres humanos en todas partes hanen definitiva despertado laconciencia jurídica universal para laapremiantenecesidad de reconceptulizarlaspropias bases delderecho internacional. Este último no se reduce, em absoluto, a un instrumental a serviciodel poder; sudestinatario final es el ser humano, debiendo atender a sus necesidades básicas, entre lacuales se destaca la de larealización de lajusticia (TRINDADE, 2006, p. 171). ${ }^{5}$
\end{abstract}

Como consequência desta necessidade de humanização do direito internacional é criada a ONU (Organização das Nações Unidas), por ocasião da Conferência de São Francisco em 26 de junho de 1945, através da Carta das Nações Unidas. Este órgão tencionava tornar a guerra algo ilícito, reorganizar o mundo para que novos conflitos armados não voltassem a ocorrer. Entre os objetivos das Nações Unidas estavam: "a promoção da dignidade humana e o respeito aos direitos fundamentais dos indivíduos; a igualdade entre as pessoas, os povos e os Estados; a promoção do progresso econômico e social; e a proibição do uso da força nas relações internacionais" (PORTELA, 2010, p. 215).

De acordo com os autores Hegarthy e Leonard (1999, p. 26), as duas razões, dentre outras, pelas quais a Carta das Nações Unidas merece destaque diz respeito, em primeiro lugar, ao fato de ter reconhecido que os direitos de uma pessoa devem ser respeitados em extensão internacional, deixando de ser uma questão exclusiva da jurisdição de um Estado. Além disso, impôs às Nações Unidas a necessidade de uma codificação dos direitos do homem, que delineou o que foi o documento internacional pioneiro sobre os direitos do indivíduo: a Declaração Universal dos Direitos Humanos, aprovada em 1948 e é considerada o documento mais importante e influente na conservação e defesa dos direitos humanos.

Neste mesmo ano, após os julgamentos realizados pelos tribunais de Nuremberg e de Tóquio, os quais tinham como principal objetivo processar e julgar os responsáveis pelas barbáries cometidas durante a Segunda Guerra, a comunidade

${ }^{5} \mathrm{As}$ atrocidades e os abusos que vitimizaram milhões de seres humanos em todos os lugares nas últimas décadas, finalmente despertaram a consciência jurídica universal para a necessidade urgente de reconceitualizar os próprios fundamentos do direito internacional. Este último não se reduz de forma alguma a um instrumento a serviço do poder; seu destinatário final é o ser humano, tendo que atender a suas necessidades básicas, dentre as quais se destaca a da realização da justiça. 
internacional reconheceu que "em todos os períodos da história o genocídio infligiu grandes perdas à humanidade" e, convencida de que a cooperação internacional era "indispensável para livrar a humanidade dessa prática odiosa" (GASPARIN JUNIOR, 2009, p. 27), a Assembléia-Geral das Nações Unidas aprovou a Convenção para a Prevenção e Repressão do Crime de Genocídio, que foi o "primeiro tratado multilateral a respeito de um crime internacional a entrar em vigor na História” (CRETELLA NETO, 2008, p. 330).

Após esse período, foram elaborados inúmeros tratados internacionais de proteção dos direitos humanos, os quais reafirmam a cidadania mundial, por meio da Convenção Europeia dos Direitos Humanos de 1950; Os Pactos Internacionais de Direitos Humanos de 1966; a Convenção Americana de Direitos Humanos de 1969; Convenção Internacional sobre Eliminação de todas as formas de discriminação racial (1965) e contra a Mulher (1979); a Carta Africana dos Direitos Humanos e dos Direitos dos Povos de 1981; Convenção contra a Tortura e outros Tratamentos ou Penas Cruéis, Desumanas ou Degradantes de 1984, apenas para citar alguns exemplos importantes.

Nota-se por este contexto que ocorreu uma evolução das relações internacionais, ficando evidente que a criação de um órgão judicial internacional para julgar os graves crimes cometidos contra a humanidade e o direito internacional se fazia imprescindível. "Partia-se do pressuposto de que uma instância judicial dessa natureza seria componente-chave na conformação de uma arquitetura multilateral para a promoção da paz" (CARDOSO, 2012, p. 25). Nesse momento, a busca fundamental "passa a ser a resolução pacífica das controvérsias e a paz por meio do direito" (BEDIN e LEVES, 2018, p. 248).

No entanto, o clima da Guerra Fria (1947-1991), que posteriormente fez com o mundo ficasse bipolarizado política e ideologicamente, não permitiu que a ideia se concretizasse. Essa realidade política constituiu durante muito tempo uma espécie de freio para o desenvolvimento do direito internacional dos direitos humanos. Mas, passado esse episódio, houve o processo de democratização de várias nações e, com isso, o tema dos direitos humanos ganhou mais espaço na agenda internacional novamente.

Muitos governos (essencialmente ocidentais) tinham começado a reconhecer um conceito de direitos humanos indivisíveis, inalienáveis, individuais, como necessários para impedir abuso de seres humanos por parte dos seus dirigentes políticos. Esses governos, com uma tendência mais socialista, ou os que recém emergiam dos legados do colonialismo, viam a autodeterminação e os direitos das comunidades e povos como chave para acabar com a opressão. Todos queriam ver 
estes objectivos em grandes letras numa especificação normativa dos direitos pela comunidade internacional e, extraindo lições do passado, muitos compreenderam que a protecção fundamental dos direitos humanos precisava de transcender tanto as fronteiras como a diplomacia política. No entanto, a maior parte estava apenas preocupada com estabelecer normas deixando que os governos nacionais as cumprissem o melhor que pudessem, em lugar de se empenharem num repensar fundamental de como é que o mundo poderia ser ordenado diferentemente para assegurar a implementação de normas mínimas de uma maneira significativa (HEGARTHY e LEONARD, 1999, p. 39).

Paradoxalmente, o Direito Internacional feito pelos Estados e para os Estados começou a tratar da proteção internacional dos direitos humanos contra o próprio Estado, único responsável reconhecido juridicamente, querendo significar este novo elemento uma mudança qualitativa para a comunidade internacional, uma vez que o direito das gentes não mais se cingiria aos interesses nacionais particulares (MAZZUOLLI, 2001, p. 104).

Após esta análise, fica evidente que o homem foi finalmente alçado à categoria de sujeito de direito internacional, tornando-se verdadeiro cidadão do mundo, com direitos humanos protegidos dentro de seu Estado ou onde quer que se encontre. Os primeiros passos haviam sido dados, era necessário que a ideia fosse amadurecida com o tempo e, condições favoráveis surgiram na década de 1990, por conta dos eventos que vieram a ocorrer com o fim da Guerra Fria e a indignação da comunidade internacional. A Organização das Nações Unidas implanta um sistema global de proteção dos Direitos Humanos, propiciando a criação dos tribunais ad hocpara ex-Iugoslávia e Ruanda, os quais tiveram papel importantíssimo e fundamental para o avanço do estabelecimento de um Tribunal Penal Internacional permanente, como se verificará a seguir.

\section{ANTECEDENTES DO TRIBUNAL PENAL INTERNACIONAL}

Como observado no capítulo anterior, a ideia de se criar um Tribunal Penal Internacional de caráter permanente para punição de indivíduos acusados de perpetrarem crimes contra os direitos humanos não era nova, pelo contrário, atendia a um pedido antigo da comunidade internacional.

Tem-se notícia que o primeiro tribunal "ad hoc" foi criado em 1474, formado por juízes da Alsácia, Áustria, Alemanha e Suíça, no intuito de julgar Peter de Hagenbach por estupro, assassinato, perjúrio e outras infrações cometidas em violação às leis de Deus e dos 
homens, durante sua ocupação da cidade de Breisach (HALL, 1998, s.p.).Antes disso, porém, em 1305, William Wallace já havia sido julgado e condenado por um tribunal inglês por crimes contra a humanidade e por ter cometido "excessos na guerra, sem poupar idade nem sexo, monge ou freira" (SARKIN, 2007, p. 19).

Ainda assim, conforme abordado no capítulo antecedente, foram necessários mais de quatro séculos e muitos episódios sangrentos, para que uma proposta séria e efetiva sobre um Tribunal Penal Internacional permanente viesse a ocorrer. Nesse sentido, a primeira proposta escrita e que se tentou discutir a respeito do Tribunal ocorreu em 1872, de autoria de Gustave Moynier ${ }^{6}$. Antes de sua sugestão, os crimes perpetrados que infringiam o Direito Internacional Humanitário eram julgados perante tribunais "ad hoc", criados normalmente pelo país beligerante vencedor, ou um tribunal comum e não por um tribunal internacional (HALL, 1998, s.p.).

Contudo, a iniciativa de Moyniere outras que vieram posteriormente - a exemplo do Tratado de Versalhes, que colocou fim a Primeira Guerra Mundial e visava o estabelecimento de uma jurisdição penal internacional - não avançaram durante o século XIX devido à resistência por parte dos Estados, que ainda não estavam maduros o suficiente para lidar com essas questões.

O debate somente ressurge após a Segunda Guerra Mundial, pois devido as suas consequências catastróficas no plano de violação de direitos, a ausência e principalmente a necessidade de se instituir uma justiça internacional permanente ficou mais evidente e foi se mostrando como a única solução possível e viável para lidar com os violentos acontecimentos. E, desta vez, os Estados, em sua maioria, estavam dispostos a fazer alterações e flexibilizações sobre suas considerações políticas internas.

Em resposta as atrocidades da Segunda Guerra, foi criado o Tribunal Militar Internacional de Nuremberg, do qual resultaram doze condenações à pena de morte, nove prisões perpétuas e três réus absolvidos.Na mesma época, também foi criado o Tribunal Militar Internacional para o Extremo Oriente, para julgar os criminosos acusados de cometerem crime de guerra e crimes contra a humanidade, na época do Japão Imperial.

Estes tribunais sofreram algumas críticas, pois eram considerados tribunais de exceção e, por isso, tinham sua legitimidade contestada sob o argumento de que foi realizada

\footnotetext{
${ }^{6}$ Um dos fundadores e durante muitos anos presidente do Comitê Internacional da Cruz Vermelha.
} 
a "Justiça dos Vencedores", o que indicava certo caráter arbitrário e injusto dos tribunais, posto que nenhum oficial pertencente aos quadros dos países vitoriosos foi julgado pelos crimes perpetrados durante a guerra. Outra crítica sofrida por estes tribunais dizia respeito ao fato de que muitas condutas praticadas na época da Segunda Guerranão estavam tipificadas como crime pelo direito internacional, o que feria o Princípio do nullum crimen nulla poena sine previa lege.

Nesse sentido, complementa Cherif Bassiouni (1997, s.p.):

These past experiences with ad hoc international tribunals confirm the need for a permanent system of international criminal justice. Because they only try certain conflicts, these tribunals and their laws and penalties raise fundamental questions about compliance with the principles of legality and about general considerations of fairness [...] Furthermore, ad hoc tribunals generally do not provide equal treatment to individuals in similar circumstances who commit similar violations. Thus, such tribunals create the appearance of uneven or unfair justice, even when the accused are properly deserving of prosecution. A permanent system of international criminal justice based on a preexisting international criminal statute would allow any person from any nation to be held accountable for violations. Equaltreatment for violatorswouldbeguaranteed ${ }^{7}$.

No entanto, dificilmente algum país do mundo pós Segunda Guerra seria, de fato, neutro e toda a articulação diplomática que seria necessária para que muitos países chegassem a um acordo geraria mais atrasos numa realidade que exigia resposta imediata. Apesar da parcela de injustiça, a alternativa seria não haver julgamento algum (EHRENFREUND, 2007, p. 48). E, mesmo com as censuras, a criação destes tribunais representou um dos acontecimentos mais importantes para a internacionalização dos direitos humanos, bem como a reconstrução do direito internacional penal, impondo limitações ao princípio da soberania dos Estados em favor dos direitos humanos, ao passo que o indivíduo começa a ter direitos reconhecidos e protegidos pelo Direito Internacional.

\footnotetext{
${ }^{7}$ Essas experiências passadas com tribunais internacionais ad hoc confirmam a necessidade de um sistema permanente de justiça criminal internacional. Porque eles só abrangiam certos conflitos, esses tribunais e suas leis e penalidades levantam questões fundamentais sobre o cumprimento dos princípios da legalidade e sobre considerações gerais de justiça [...] Além disso, tribunais ad hoc geralmente não oferecem tratamento igual para indivíduos que cometeram violações semelhantes. Assim, tais tribunais criam a aparência de justiça desigual ou injusta, mesmo quando os acusados são devidamente merecedores de processo. Um sistema permanente de justiça penal internacional baseado em um estatuto criminal internacional preexistente permitiria que qualquer pessoa de qualquer nação fosse responsabilizada por violações. A igualdade de tratamento para os violadores seria garantida
} 
Outro fator importante é que estes órgãos evidenciaram o "vazio jurídico" em razão da inexistência de uma instituição internacional independente, baseado num instrumento jurídico com abrangência universal, que pudesse proteger o indivíduo e processar os responsáveis pelos crimes mais graves de interesse mundial (GASPARIN JUNIOR, 2009, p. $50)$.

De acordo com o entendimento de Celso Lafer (1988, p. 169):

\begin{abstract}
A concepção de um Direito Internacional Penal com Nuremberg e Tóquio ensejaram a compreensão ético-jurídica-política que existem certas exigências fundamentais da vida na sociedade internacional e que a violação das regras relativas a tais exigências constituem crimes internacionais específicos.
\end{abstract}

Assim, estas duas experiências representam marcos fundamentais para a constituição definitiva do Tribunal Penal Internacional. No entanto, não foram as únicas e a elas devem ser somadas a criação dos tribunais penais internacionais para a antiga Iugoslávia (1993) e para Ruanda (1994).

Os conflitos na região da ex-República Socialista Federal da Iugoslávia remontam à Antiguidade, mas seu colapso se deu por volta de 1991. Neste contexto, os crimes perpetrados neste conflito foram significativos e evidenciaram ofensas aos direitos humanos. Por isso, e sofrendo uma grande pressão internacional, a ONU criou através de seu Conselho de Segurança o Tribunal Penal Internacional ad hoc para a ex-Iugoslávia, com o intuito de “julgar as pessoas consideradas responsáveis por violações graves ao direito internacional humanitário, cometidas no território da ex-Iugoslávia, a partir de 1991" (art. $1^{\text {0 }}$ do Estatuto do Tribunal da ex-Iugoslávia).

Um ano depois, em 1994, explodiram os conflitos em Ruanda, país africano dividido em duas etnias: tutsis e hutus. Os crimes cometidos em um curto espaço de tempo (três meses) foram gravíssimos e contabilizaram quase um milhão de mortos. Por isso, o Conselho de Segurança das Nações Unidas criou, em 1995, o Tribunal Penal Internacional ad hoc para Ruanda com o objetivo de:

Julgar as pessoas consideradas responsáveis por violações graves ao direitointernacional humanitário cometidas no território de Ruanda, bem como os cidadãos ruandeses considerados responsáveis por essas violações cometidas no território de Estados vizinhos, entre $1^{\circ}$ de janeiro e 31 de dezembro de 1994 (art. $1^{\circ}$ do Estatuto do Tribunal de Ruanda). 
Estes dois tribunais também tiveram críticas, por serem ad hoc em relação aos julgamentos dos criminosos e crimes por eles cometidos, além da sua forma de instituição, feita através de Resoluções do Conselho de Segurança da ONU e não por tratado multilateral, o que caracterizava a aparente prevalência da paz e não da justiça. No entanto, deixaram importante legado e muito contribuíram para o tema da responsabilidade do indivíduo por crimes contra os direitos humanos, ao mesmo tempo em que reforçaram a necessidade de proteção efetiva desses direitos através da criação de um órgão penal internacional permanente.

Assim, em 1994, a Comissão de Direito Internacional submeteu à Assembleia Geral das Nações Unidas, um projeto de Estatuto para um futuro Tribunal Penal Internacional. Após um processo de revisões e alterações do conteúdo, bem como pesquisas e contribuições oriundas de outras fontes, finalmente, em dezembro de 1996, a Assembleia Geral da ONU, através da Resolução nº 51/207, decidiu que a Conferência Diplomática dos Plenipotenciários para a criação do TPI, como sugerido pela Comissão, seria realizada em 1998, marcando o aniversário de 50 anos de dois documentos importantes, senão os principais das Nações Unidas, quais sejam a Convenção para a Prevenção e Repressão do Crime de Genocídio e a Declaração Universal dos Direitos Humanos. A Assembleia, atendendo a um oferecimento da Itália, escolheu Roma para sediar a Conferência (GASPARIN JUNIOR, 2009, p. 51).

Assim sendo, entre 15 de junho e 17 de julho de 1998, foi realizada a Conferência Diplomática de Plenipotenciários para o estabelecimento de um Tribunal Penal Internacional, nas dependências da FAO (FoodandAgricultureOrganizationof United Nations), na cidade de Roma, Itália. No dia 17 de julho de 1998, foi adotado o Estatuto de Roma, pelos países que participaram da Conferência, preenchendo a lacuna institucional no plano internacional, com sede em Haia, nos Países Baixos.

As sessenta ratificações necessárias foram alcançadas em 11 de abril de 2002, sendo que em $1^{\circ}$ de julho de 2002 entrou oficialmente em vigor o Tratado de Roma sobre o Tribunal Penal Internacional, com 76 ratificações e 136 assinaturas (GORAIEB, 2012, p. 150).

O texto aprovado na Conferência de Roma restringiu-se a quatro categorias, denominadas de core crimes e representam os delitos mais graves, de transcendência internacional, a saber: crime de genocídio, crimes contra a humanidade, crimes de guerra e crime de agressão. 
Contando atualmente com 24 casos e situações sob investigação (ICC-CPI, 2007), a constatação da relevância de sua criação é notória sendo considerado um dos instrumentos legais mais relevantes deste século, pois reúne antigos e diversos anseios de ordem internacional, no sentido de buscar a preservação da paz e efetiva proteção internacional dos direitos humanos. Ainda, permiteo julgamento e punição dos responsáveis por perpetrarem os crimes mais abomináveis violadores do Direito Internacional, o que representa uma vitória contra a impunidade.

Desta forma, alguns obstáculos ainda existem para serem transpostos, no sentido de alcançar a justiça mais ampla com uma atuação rápida e eficiente do Tribunal que, para isso, necessita da colaboração dos Estados para se alcançar a vocação internacional, punição e efetiva proteção dos direitos humanos no âmbito internacional, como se verá a seguir..

\section{DESAFIOS E PERSPECTIVAS DO TRIBUNAL PENAL INTERNACIONAL NA REALIADADE CONTEMPORÂNEA}

Atualmente, existe um consenso de que os crimes internacionais são aqueles que implicam em: violações às normas costumeiras internacionais, abrangendo também os tratados e convenções; regras que tem como objetivo proteger valores importantes internacionalmente e, por isso, obrigatórias a todos os Estados e indivíduos; existência de um interesse universal na prevenção e repressão destes crimes. Representam, assim, as infrações mais graves, aquelas que violam direitos humanos fundamentais (JANKOV, 2009, p. 57-59).

Apesar dos numerosos tratados e instrumentos de direitos humanos que se multiplicaram a partir dos acontecimentos pós Segunda Guerra e da Declaração Universal de 1948, conforme explanado anteriormente, observa-se ainda hoje, de forma muito rotineira, a contínua violação aos direitos humanos.Paralelamente a esta ideia, um dos grandes avanços ocorridos na seara da proteção internacional dos direitos humanos, é o acesso que os indivíduos passaram a ter às instâncias internacionais bem como a consolidação de sua capacidade processual internacional nas situações de atentados dos direitos humanos (TRINDADE, 1997, p. 170).

Hoje é inconcebível a prática desses atos cruéis e a humanidade precisa caminhar no sentido de evoluir e se ver livre dessas perversidades. Nesse sentido, parece ter 
razão Norberto Bobbio (2009, p. 11) ao afirmar que "se alguém me perguntar quais são, na minha opinião, os problemas fundamentais do nosso tempo, não tenho qualquer hesitação em responder: o problema dos direitos do homem e o problema da paz". Assim, é possível asseverar que ao mesmo tempo em que a comunidade internacional foi se alargando para se tornar mais universal e abraçar todos os povos, inversamente proporcional tornou-se a falta de segurança e a necessidade de proteção dos direitos humanos e manutenção da paz.

Um entrave importante tem-se mostrado no caminho dessa evolução, representado pela multiplicidade de mecanismos internacionais, aliada à falta de cooperação entre os Estados, que teimam em nãoflexibilizar sua soberania a fim de se chegar a uma justiça de alcance universal para a proteção efetiva dos direitos humanos.Em outras palavras, para a efetiva proteção dos direitos humanos de um indivíduo urge que os Estados se disponham a cooperar com as investigações e julgamentos quando os crimes não só ocorreram dentro de seu território, mas também quando os acusados estiverem sob sua proteção. Além disso, é importante que, estes mesmos Estados reafirmem sua soberania ao incorporarem em seus ordenamentos internos mecanismos para a proteção dos direitos humanos.

Em termos teóricos o Tribunal Penal Internacional deveria ser uma instituição que se enquadraria na categoria de organizações internacionais de alcance universal, que são representadas por "todas aquelas vocacionadas para acolher o maior número possível de Estados, sem restrição de índole geográfica, cultural, econômica ou outra", bem como na categoria de instituições de domínio político, “assim vistas aquelas que se consagram sobretudo à preservação da paz e da segurança, embora cuidem, ancilarmente, de outros propósitos" (REZEK, 2008, p. 263).

Por outro lado, em termos práticos, a jurisdição universal do TPI somente se verificaria se houvesse ratificação mundial do Estatuto de Roma.No entanto, essa pretensa vocação universal sofre certa limitação e o artigo 12 do Estatuto estabelece o mecanismo para o exercício da jurisdição do TPI. Nesse sentido foi adotado o princípio da competência automática ou inerente, pois o Estado que se torna parte, aceita se submeter à jurisdição do Tribunal com relação aos crimes de sua competência material. O Estatuto prevê, também, a possibilidade de um Estado não membro aceitar a jurisdição do TPI, posteriormente, através de declaração.

No tocante aos vínculos, é interessante observar que, se por um lado o indivíduo estará protegido tanto em ambiente interno quanto fora de seu território, por outro, 
no caso do indivíduo que vier a perpetrar crimes, este também poderá ser punido pessoalmente em âmbito internacional. Neste caso, o TPI poderá exercer sua jurisdição se um ou mais Estados forem parte no Estatuto quando: o Estado em cujo território o crime ocorreu ou o Estado de nacionalidade do acusado. Esses requisitos não são cumulativos, por isso, é possível que o TPI venha a processar e julgar crimes que tenham sido cometidos por nacionais de um Estado não parte - se o delito tiver ocorrido em território de um Estado parte - ou no território de um Estado não parte - se o delito tiver sido perpetrado por um nacional de Estado parte (CARDOSO, 2012, p. 64).

Importante observar que, apesar da resistência em sua aplicação, a regra constante no TPI, a qual permite que um cidadão de um Estado não parte seja julgado pelo Tribunal, na verdade reproduz o princípio da territorialidade da lei penal, em vigor nos sistemas penais nacionais. Independente da nacionalidade da vítima, cabe ao Estado processar e julgar crimes que ocorram em seu território, podendo transferir para o TPI a competência, nos termos do Estatuto.Por isso, o instrumento multilateral não ataca direitos de Estados não parte, pois a jurisdição do TPI exercida sobre o território dos Estados parte, na ocorrência de um crime previsto no Estatuto não é diferente da competência territorial prevista no ordenamento jurídico interno de praticamente todos os países (CARDOSO, 2012, p. 65).

Ademais, a regra adotada no Estatuto do Tribunal somente poderia implicar num alcance universal, se todos os países aceitassem participar deste mecanismo. E, atualmente, apenas 122 Estados são partes no Estatuto, sendo que dos cinco membros permanentes do Conselho de Segurança das Nações Unidas, Estados Unidos, Russia, China, França e Inglaterra, apenas dois são membros do Estatuto de Roma: Inglaterra e França. Tal fato dificulta e afeta a credibilidade do Tribunal, que tem o exercício pleno de suas funções muito dependente das atitudes tomadas pelos Estados Unidos, China e Rússia no contexto do Conselho de Segurança. No entanto, a busca da universalidade e tentativa de fazer do TPI um instrumento efetivo da justiça penal internacional a nível mundial continuará no futuro, mesmo com os obstáculos presentes.

Nesse contexto, urge salientar que o Estatuto de Roma afirmou o Princípio da Complementaridade em relação à atuação do Tribunal, pois num primeiro momento, são os Estados e não o Tribunal quem tem competência para investigar e processar os crimes. No TPI o princípio da complementaridade é afirmado desde o preâmbulo do Estatuto, quando prevê que o “[...] Tribunal Penal Internacional, criado pelo presente Estatuto, será 
complementar às jurisdições penais nacionais". O princípio também é reafirmado no artigo $1^{\circ}$ do Estatuto.

Assim, percebe-se que, o Estado tem jurisdição em primeiro plano, quando capaz de investigar e realizar a persecução penal. Se o Tribunal concluir que a jurisdição nacional é confiável, dará preferência a ela. Por outro lado, será o Tribunal competente se concluir que o Estado não está disposto a agir em um determinado caso, seja por falta de vontade ou por impossibilidade. O parágrafo $2^{\circ}$ do artigo 17 do Estatuto define os critérios que serão utilizados como base para determinar a falta de vontade ou incapacidade de agir em uma determinada situação (GORAIEB, 2012, p. 152).

A complementaridade do Tribunal representa importante passo para efetiva proteção internacional dos direitos humanos, pois de certa forma obriga os Estados a adequarem seus sistemas judiciais dos instrumentos normativos e processuais para aplicar a justiça de forma eficaz e equânime (SABÓIA, s.d., p. 3) sob pena dos crimes passarem a ser julgados pelo TPI.O que se espera com essa medida, é que haja convergência entre o Tribunal e os Estados nacionais, na constituição de uma justiça internacional, que tem como objetivo um denominador comum representado pela tutela dos bens jurídicos mais caros à humanidade.

Nesse sentido, com razão afirma Zilli (2013, p. 173):

$\mathrm{Na}$ verdade, não é possível que um único órgão internacional exerça, com exclusividade, a jurisdição frente a todos os crimes internacionais. Se assim o fosse, certamente a efetividade da ordem penal internacional estaria comprometida. $\mathrm{Na}$ verdade, o que se pretende é que os Estados aprimorem os seus respectivos sistemas jurídicos, afastando os possíveis entraves à persecução dos crimes internacionais no âmbito de suas próprias jurisdições domésticas. Esse ideal está assentado no próprio preâmbulo do ER ao se reconhecer que a repressão daqueles atos há de ser realizada com adoção de medidas tanto no plano nacional, quanto na esfera internacional (ZILLI, 2013, p. 173).

Assim, embora o TPI tenha sido criado para suprir as deficiências dos sistemas positivos nacionais, o que se espera é que haja convergência entre o Tribunal e os Estados nacionais, na constituição de uma justiça internacional, que tem como objetivo um denominador comum representado pela tutela dos bens jurídicos mais caros à humanidade. Da

Antes mesmo de o Tribunal Penal Internacional começar a funcionar, era previsível que alguns Estados, principalmente os mais pobres, diante dos problemas que 
enfrentam em seus sistemas judiciais, bem como aqueles que estão envolvidos ou se recuperando de uma situação de conflito, não teriam condições de implementar o Estatuto. Daí a importância da cooperação internacional com o objetivo de assegurar que os países participantes do mecanismo estejam em condições iguais de atuar, com seus sistemas nacionais em primeiro plano, com atuação do TPI em caráter excepcional.

Neste contexto, a questão da soberania dos Estados vem à tona e nota-se atualmente que seu conceito encontra-se relativizado em prol da proteção internacional dos direitos humanos. A soberania não consiste mais, hoje em dia, na liberdade de um Estado agir independente e isoladamente, visando apenas seu interesse específico e próprio. A soberania diz respeito a uma cooperação internacional em benefício de um objetivo comum. Ao participar desta comunidade o Estado expressa e realiza sua soberania. Fazer parte do sistema internacional é um ato de soberania por excelência (MAZZUOLI, 2004, p. 354).

O novo conceito de soberania foi-se construindo juntamente com o processo de internacionalização dos direitos humanos. A soberania que antes era tida como absoluta sofreu uma relativização e flexibilização na nova ordem mundial, onde o indivíduo passa a contar com duplo grau de proteção: um interno, que lhe é garantido pelo Estado ao qual pertence, e outro garantido no âmbito internacional. Assim, o processo de consolidação do indivíduo como sujeito de direito na esfera internacional se concretiza juntamente com o progressivo fortalecimento do direito internacional (GASPARIN JUNIOR, 2009, p. 95).

Os direitos humanos fazem parte da chamada agenda global das relações internacionais. O ponto principal aqui é que o sentido de humanidade passa a ser o princípio regulador da comunidade internacional e representa a constituição e institucionalização do bem comum em nível universal, onde se argumenta a legitimidade das condutas internas e internacionais da soberania.

Ainda hoje existe uma proliferação de conflitos violentos internos bem como entre os Estados em diversas partes do mundo, causando uma denegação total dos direitos humanos para alguns grupos. A grave violação dos direitos humanos, com o detrimento dos direitos civis e políticos, somada às discriminações por razões étnicas, culturais, religiosas contra grupos vulneráveis e minorias e, principalmente, o atentado rotineiro aos direitos fundamentais e direito internacional humanitário tem se mostrado cada vez mais preocupante e indicam um certo grau de retrocesso dos direitos e garantias protegidos. 
Se por um lado é inegável o avanço no campo da proteção e efetivação dos direitos humanos, este processo não tem sido linear. Existe, atualmente, uma diversificação na origem dessas violações, o que faz concluir pela necessidade de uma revisão do atual sistema. Nesse sentido é que o Tribunal Penal Internacional se mostra como importante instrumento para a efetivação da proteção do direito internacional dos direitos humanos. Em contrapartida, precisa ainda, se redefinir enquanto mecanismo em uma visão de esvaziamento dos parâmetros teóricos dos séculos passados em prol da efetiva proteção internacional dos direitos humanos, como uma finalidade única e comum a todos.

Fato é que com a adoção do Estatuto de Roma, há uma leitura otimista em razão da importância do passo que foi dado no sentido de criar uma instituição internacional de caráter permanente. Assim, ainda que exista o anseio de que o Tribunal Penal Internacional tenha mais poderes em sua atuação, a verdade é que a sua constituição e criação não pode ser de forma alguma minimizada, pois representa um presente para as futuras gerações e um enorme passo em busca da justiça internacional da forma mais plena e eficiente possível, com relação a todos os seus aspectos: permanência, independência, complementaridade e a vocação universal, ou pelo menos a não particularização a situações específicas e o mais importante, a busca pelo fim da impunidade.

\section{CONCLUSÃO}

Embora com ressalvas, dadas as dificuldades para alcançar sua universalidade bem como a necessidade de cooperação entre os Estados, que quase nunca estão dispostos a abrir mão de sua soberania, a relevância do Tribunal Penal Internacional para a efetivação da proteção dos direitos humanos no plano internacional e para o desenvolvimento de uma pretensa justiça universal pode ser sentida.

Após incontáveis episódios e formas distintas de violação dos direitos humanos, estes passaram por um processo de internacionalização e consolidação dentro do próprio direito internacional. Por isso, a ideia de criação de um Tribunal Penal Internacional de caráter permanente era antiga, mas condições favoráveis para a sua instituição só ocorreram na década de 1990, com a afirmação de um ideal comum na busca pelo fim da impunidade e proteção dos direitos humanos em nível internacional. 
O século XX representa um período de grande avanço tecnológico, ao mesmo tempo e, como consequência disso, o mundo assiste a grandes violações dos direitos humanos em diversos pontos do globo. Crimes até então inimagináveis foram perpetrados no mundo todo e, por tal motivo, se encontrou um terreno fértil para que o direito internacional dos direitos humanos se desenvolvesse e ganhasse seu mais alto grau de proteção através da criação de um mecanismo internacional.

O Tribunal Penal Internacional representa um esforço para que se colocasse em funcionamento desde os primeiros anos deste século um mecanismo com caráter permanente e independente, que contasse com personalidade jurídica própria, complementar aos sistemas jurídicos nacionais e, competente para processar e julgar indivíduos acusados de cometerem graves crimes de transcendência internacional: genocídio, crimes de guerra, crimes contra a humanidade e crimes de agressão.

Nesse sentido, verificou-se que a permanência é um dos traços marcantes do Tribunal, em contraste com o caráter temporário dos tribunais ad hoc criados pelo Conselho de Segurança da ONU. Outra característica importante e essencial para o funcionamento do TPI é a sua independência e o fato do Procurador ter autonomia para iniciar uma investigação por contra própria e acionar a jurisdição do TPI, é a chave para o funcionamento do sistema.

O caráter da complementaridade é o fundamento do Estatuto de Roma e afirma que os Estados é que tem primazia para processar e julgar crimes sob sua jurisdição. Esta característica muito contribui para que haja um desenvolvimento dos sistemas jurídicos nacionais, que terão de desenvolver mecanismos processuais eficazes para aplicar a justiça em relação aos crimes previstos no Estatuto, que passam a fazer parte do direito interno dos países que o ratificaram.

Para os países que aderiram à Corte, não existe restrição ou diminuição de sua soberania. Pelo contrário, tal atitude representa um verdadeiro ato de soberania, pois ratifica um tratado multilateral que tem o objetivo de trazer bem estar para a sociedade internacional e o faz de acordo com a sua Constituição. Hoje, o novo conceito de soberania deve ser vislumbrado sob a ótica da proteção dos direitos humanos, os quais devem prevalecer.

Os crimes previstos no Estatuto de Roma estão intimamente ligados à temática dos direitos humanos e direito humanitário. Através do Tribunal reafirma-se a responsabilidade penal internacional individual. Referidos delitos tendem a ser cometidos em situações de guerras e conflitos políticos, em que muitas vezes os criminosos são membros do 
Governo ou de grupos não estatais. Na maioria das vezes estes indivíduos ficavam impunes porque gozavam de imunidades, nos termos de suas legislações internas. A gravidade do crime também conta e o Tribunal deverá atuar somente em situações excepcionais.

Em se tratando de elementos coercitivos, o Tribunal depende totalmente da cooperação dos Estados parte, que é um componente fundamental para lhe garantir o funcionamento e eficiência. Cabe às autoridades nacionais cooperar com a instituição e cumprir suas determinações. O Estatuto conta com amplo grau de aceitação entre os Estados. A maior parte dos membros da ONU é parte do TPI.

O que impede a universalidade do regime do Tribunal são os países que não ratificaram e não dão mostras de que o farão num horizonte próximo. As potências China, Estados Unidos, Rússia e a Índia, além de grande parte dos países árabes, não ratificaram o Estatuto até o momento, principalmente por não aceitarem a jurisdição do TPI sobre seu território ou para julgar seus nacionais. No entanto, é desejável caminhar em direção à universalidade de sua jurisdição.

O TPI representa a concretização de um sonho dos que lutam por Justiça e buscam punir e retirar do convívio coletivo mundial os criminosos mais impiedosos, capazes de cometer os crimes mais bárbaros e em relação aos quais não mais se admite o seu esquecimento.Atualmente, a posição do ser humano como titular de direitos próprios, oponíveis a todos os Estados, inclusive o de sua nacionalidade ou o Estado em cuja jurisdição se encontre, constitui uma verdade inviolável e demonstra a inovação revolucionária que aconteceu no Direito Internacional após a Segunda Guerra Mundial.

Por isso, o Tribunal Penal Internacional representa um avanço para a humanidade, é instrumento que reafirma a esperança e a fé nos direitos humanos fundamentais. É, contudo, uma obra em construção, e muito ainda deve ser feito para que o TPI se torne o instrumento que se propôs a operar, por meio de seus princípios fundantes. $\mathrm{O}$ Tribunal tem diversos desafios a enfrentar que trazem implicações para a consolidação da própria instituição. A falta de aceitação universal representa o maior obstáculo para o Tribunal ganhar credibilidade. Credibilidade que dependerá, também, de uma atuação coerente, equilibrada e não politizada, em conformidade com os ideais de justiça, cuja humanidade busca alcançar a séculos e tem pagado um preço muito caro até agora. 


\section{BIBLIOGRAFIA}

BASSIOUNI, M. Cherif. From Versailles to Rwanda in seventy-five years: the need to establish a permanent international criminal court. Harvard Human Rights Journal, n. 10.Cambridge, Nov. 1997, p. 11-63.

BOBBIO, Norberto. O terceiro ausente: ensaios e discursos sobre a paz e a guerra. São Paulo: Manole, 2009.

Bobbitt, Philip. A guerra e a paz na história moderna: o impacto dos grandes conflitos e da política na formação das nações. Tradução Cristiana Serra. Rio de Janeiro: Campus, 2003.

CHOUKR, Fauzi Hassan; KAI, Ambos (orgs.). Tribunal Penal Internacional. São Paulo: Editora Revista dos Tribunais, 2000.

CLAUSEWITZ, Carl Von. Da guerra. São Paulo: WMF Martins Fontes, 2010.

CARDOSO, Elio. Tribunal penal internacional: conceitos, realidades e implicações para o Brasil. Brasília: Funag, 2012.

COMPARATO, Fábio Konder. A afirmação história dos direito humanos.7 ed. rev., e atual.São Paulo: Saraiva, 2010.

CRETELLA NETO, José. Curso de direito internacional penal. Ijuí: Unijuí, 2008.

EHRENFREUND, Norbert. The Nuremberg Legacy: How the nazi war crime trials changed the course of history. New York: PalgraveMacmillan, 2007.

FERNANDES, Antônio Scarance; ZILLI, Marcos Alexandre Coelho (Coord.). Direito processual penal internacional. São Paulo: Atlas, 2013.

FERNANDES, David Augusto. Tribunal Penal Internacional: a concretização de um sonho. Rio de Janeiro: Renovar, 2006. 
FERRAJIOLI, Luigi. A soberania no mundo moderno: nascimento e crise do Estado nacional. Tradução de Carlo Coccioli e Márcio Lauria Filho. São Paulo: Martins Fontes, 2002.

GASPARIN JUNIOR, Nelson R. O Tribunal Penal Internacional: soberania, elementos institucionais e sua implementação no Brasil. 2009. 158 p. Dissertação (Mestrado). Universidade Federal Fluminense, Niterói, 2009.

GILBERT, Martin. A segunda guerra mundial. Tradução Ana Luísa Faria e Miguel Serras Pereira. Córdova: Dom Quixote, 2009.

GORAIEB, Elizabeth. Tribunal penal internacional: trajetórias legais em busca de justiça. São Paulo: LetrasJurídicas, 2012.

HALL, Christopher Keith.The first proposal for a permanent international criminal court.Revista Internacional da Cruz Vermelha, $\mathrm{n}^{\mathbf{o}}$ 322. Mar. 1998. Disponível em:< http://www.icrc.org/eng/resources/documents/misc/57jp4m.htm>. Acesso em 31 mai. 2018.

HEGARTHY, Angela; LEONARD, Siobhan. Direitos do Homem: uma agenda para o século XXI. Tradução: João C.S. Duarte. Lisboa, Portugal: Instituto Piaget, 1999.

HOBBES, Thomas. Leviatã: ou matéria, forma e poder de um estado eclesiástico e civil. Tradução Rosina D’Angina. 2ed. São Paulo: Martin Claret, 2012.

ICC-CPI, International Criminal Court. Situationsand Cases. 2018. Disponível em:<http://www.icc-cpi.int/Pages/cases.aspx>. Acesso em 10 set. 2018.

JANKOV, Fernanda Florentino Fernandez. Direito Internacional Penal: mecanismo de implementação do Tribunal Penal Internacional. São Paulo: Saraiva, 2009.

KANT, Immanuel. Ideia de uma historia universal de um ponto de vista cosmopolita. Tradução de Rodrigo Naves e Ricardo Terra. São Paulo: Martins Fontes, 2003.

KELSEN, Hans. A paz pelo direito. São Paulo: Martins Fontes, 2011.

LAFER, Celso. A reconstrução dos direitos humanos: um diálogo com o pensamento de Hannah Arendt. São Paulo: Companhia das Letras, 1998. 
MAZZUOLI, Valério de Oliveira. Direito internacional: tratados e direitos humanos fundamentais na ordem jurídica brasileira. Rio de Janeiro: América Jurídica, 2001.

Direitos humanos, Constituição e os tratados internacionais: estudo analítico da situação e aplicação do tratado na ordem jurídica brasileira. São Paulo: Ed. Juarez de Oliveira, 2002.

Tribunal penal internacional e o direito brasileiro. 2 ed. rev. e amp. São Paulo: Revista dos Tribunais, 2009.

MENEZES, Wagner. Tribunais internacionais: jurisdição e competência. São Paulo: Saraiva, 2013.

PERRONE-MOISÉS, Cláudia. Direito internacional penal:imunidades e anistias. Barueri, São Paulo: Manole, 2012.

PIOVESAN, Flávia. Direitos humanos e o direito constitucional internacional. 13 ed., rev. e atual. São Paulo: Saraiva, 2012.

PORTELA, Paulo Henrique Gonçalves. Direito internacional público e privado: incluindo noções de direitos humanos e de direito comunitário. 2 ed. rev., amp. e atual. Salvador: Juspodivm, 2010.

POWER, Samantha. Genocídio: a retórica americana em questão. Tradução: Laura Teixeira Motta. São Paulo: Companhia das Letras, 2004.

REZEK, José Francisco. Direito Internacional Público: curso elementar. 11 ed. rev. e atual. São Paulo: Saraiva, 2008.

SABÓIA, Gilberto Vergne. A criação do Tribunal Penal Internacional. Disponível em: <http://www.dhnet.org.br/direitos/sip/tpi/tpi_saboia.html>. Acesso em 03 mai. 2014.

SARKIN, Jeremy. The Historical Origins, Convergence and Interrelationship of International Human Rights Law, International Humanitarian Law, International Criminal Law and Public International Law and Their Application from at Least the Nineteenth Century (November 20, 
2008). Human Rights and International Legal Discourse, Vol 1, 2007; Hofstra Univ. Legal Studies Research Paper No. 08-24. Disponível em: <http://ssrn.com/abstract=1304613> Acesso em 20 mar. 2018.

SCHABBAS, William. An introduction to the international criminal court.Cambridge University Press, 2001.

SILVA, Carlos Augusto Canêdo Gonçalves da.O genocídio como crime internacional. Belo Horizonte: Del Rey, 1998.

TRINDADE, Antônio Augusto Cançado.Dilemas e desafios da proteção internacional dos direitos humanos no limiar do século XXI. Disponível em:< http://www.scielo.br/pdf/rbpi/v40n1/v40n1a07.pdf > Acesso em 15 jun. 2018.

A humanização do direito internacional. Belo Horizonte: Del Rey, 2006.

ZILLI, 